Article

\title{
Surface Probing by Spectroscopy on Titania-Supported Gold Nanoparticles for a Photoreductive Application
}

\author{
Matteo Compagnoni ${ }^{1}$, Alberto Villa ${ }^{1}{ }^{\circledR}$, Elnaz Bahdori ${ }^{1}$, David J. Morgan ${ }^{2}{ }^{\circledR}$, Laura Prati ${ }^{1}{ }^{(D}$, \\ Nikolaos Dimitratos ${ }^{2}$, Ilenia Rossetti ${ }^{1}$ (D) and Gianguido Ramis ${ }^{3, *(D)}$ \\ 1 Dipartimento di Chimica, Università degli Studi di Milano, INSTM Unit Milano-Università and CNR-ISTM, \\ via C. Golgi, 19, I-20133 Milan, Italy; matteo.compagnoni.chemistry@gmail.com (M.C.); \\ alberto.villa@unimi.it (A.V.); 713578@unige.it (E.B.); Laura.Prati@unimi.it (L.P.); ilenia.rossetti@unimi.it (I.R.) \\ 2 Cardiff Catalysis Institute, School of Chemistry, Cardiff University, Main Building, Park Place, Cardiff, \\ CF103AT, UK; MorganDJ3@cardiff.ac.uk (D.J.M.); DimitratosN@cardiff.ac.uk (N.D.) \\ 3 Dipartimento di Ingegneria Civile, Chimica e Ambientale, Università degli Studi di Genova and INSTM \\ Unit Genova, via all'Opera Pia 15A, I-16145 Genoa, Italy \\ * Correspondence: gianguidoramis@unige.it; Tel.: +39-010-353-6027
}

Received: 12 November 2018; Accepted: 29 November 2018; Published: 5 December 2018

check for updates

\begin{abstract}
The continuous increase in scientific reports concerning photocatalysis and in particular $\mathrm{CO}_{2}$ photoreduction in recent years reveals the high degree of interest around the topic. However, the adsorption and activation mechanisms of $\mathrm{CO}_{2}$ on $\mathrm{TiO}_{2}$, the most used photocatalyst, are poorly understood and investigated. Gold nanoparticles were prepared by a modified deposition-precipitation method using urea and a chemical reductant. Bare P25 was used as reference. Combined spectroscopic investigations of fresh and spent samples with photoactivity studies reported in this article provide new insights to the role of $\mathrm{CO}_{2}$ adsorption and carbonate formation on $\mathrm{Au} / \mathrm{TiO}_{2}$ during $\mathrm{CO}_{2}$ photocatalytic reduction. The key intermediates' and products' adsorption (CO, methanol, ethanol) was studied, coupled with X-ray photoelectron microscopy (XPS) and UV-Visible spectroscopy. The adsorption of $\mathrm{CO}_{2}$ on fresh and spent catalysts changes radically considering the carbonate formation and the gold surface presence. Methanol and ethanol revealed new adsorbed species on Au with respect to bare titania. The characterisation of the spent catalysts revealed the good stability of these samples.
\end{abstract}

Keywords: $\mathrm{CO}_{2}$ reduction; diffuse reflectance infrared Fourier transform spectroscopy (DRIFTS); photoreduction; protoreactor; gold; Titania; photocatalysis; high pressure

\section{Introduction}

In order to contain the emissions of greenhouse gases, $\mathrm{CO}_{2}$ photoconversion is one of the most intriguing processes from both an applicative and scientific point of view. In recent years, numerous reports relating to photocatalytic reduction of $\mathrm{CO}_{2}$ under $\mathrm{UV}$ and visible light irradiation have been presented [1-3]. However, the photoreduction mechanism is still a matter of debate, even for $\mathrm{TiO}_{2}$, which is the most studied photocatalyst. In particular, the $\mathrm{CO}_{2}$ adsorption and activation mechanism (an important preceding step in $\mathrm{CO}_{2}$ reduction) is not clear. For instance, Liu et al. investigated engineered oxygen-deficient blue $\mathrm{TiO}_{2}$ nanocrystals for $\mathrm{CO}_{2}$ photoreduction under visible light using diffuse reflectance infrared Fourier transform spectroscopy (DRIFTS) analysis, revealing different activity depending on the exposed facets, but without completely clarifying the adsorption and reaction mechanisms for the whole material [2]. By contrast Li et al. revealed how the presence of different 
crystalline phases influence the photoreduction process, detecting the presence of unique interfacial trapping sites and possibly photocatalytic "hot spots" [4].

A comprehensive study of high pressure $\mathrm{CO}_{2}$ photoconversion was carried out in one of our previous papers in order to shed light on the complex reaction mechanisms that occur both in the liquid and gas phases [5]. In such cases, a $\mathrm{TiO}_{2}-\mathrm{P} 25$ photocatalyst was chosen as a reference material and products' distribution was compared after different reaction times and $\mathrm{pH}$ conditions. Two parallel reaction pathways were observed: (i) the first one involving the photoreduction of molecular carbon dioxide to formic acid, formaldehyde, and methanol, which may further evolve to gas phase products (photoreforming); (ii) the second one implying the reduction of carbonates to give formaldehyde and possibly methanol, or formic acid/reformate as a further consecutive step.

However, the choice of $\mathrm{TiO}_{2}$ as a photocatalyst for $\mathrm{CO}_{2}$ reduction is difficult, due to the lack of photoresponse under visible light irradiation and high electron-hole recombination rate. Its light absorption onset starts at wavelengths shorter than $380 \mathrm{~nm}$ as a consequence of the wide band gap [6], just in the border between the UV and the visible region. Solar light contains only $4 \%$ of the energy in the UV region able to promote photoexcitation of titania, therefore a large proportion of the light is useless, limiting the efficiency of the process. The extension of the photoresponse towards the visible region can be achieved by metal doping [6], doping by non-metallic elements with creation of oxygen vacancies [7] and, more recently, by deposition of noble metal nanoparticles (NPs) with a surface plasmon band, particularly Au [8], Ag [9], or doping with metal-organic molecules [10].

The addition of a metal or dopant further increases the complexity of adsorption and activation mechanisms during the process. Tahir et al. investigated how the surface plasmon resonance excitation influences the reaction pathways using $\mathrm{Au} / \mathrm{Ag}$ nanoparticles on $\mathrm{TiO}_{2}$ nanowires [3]. The excited electrons in the $\mathrm{Au} / \mathrm{Ag}$ are injected into the conductance band of $\mathrm{TiO}_{2}$, making them react easily with $\mathrm{CO}_{2}$ and $\mathrm{H}^{+}$radicals, forming $\mathrm{CO}, \mathrm{CH}_{3} \mathrm{OH}$, and $\mathrm{CH}_{4}$.

Moreover, the deposition method of the metal or dopant deeply affects the resulting material and its performance, e.g., gold nanoparticles supported on oxides [11,12]. Morphology, size, metal oxidation state, and metal-support interaction deep modify activity and/or the selectivity of the whole catalyst. Therefore, a lot of attention has been paid to the preparation of gold catalysts in order to assess as much as possible the relation between preparation method and characteristics of the produced materials. Dimitratos et al. reported a detailed study concerning the effect of preparation method (deposition-precipitation versus sol immobilisation method) and reduction method (calcination versus chemical reduction) on $\mathrm{Au} / \mathrm{TiO}_{2}$ catalysts for the liquid phase oxidation of glycerol [12]. The work demonstrated the crucial role of Au oxidation state and gold particles' dimensions depending on the method and conditions adopted. In another work, Villa et al. reported an alternative sol immobilization route for the deposition of $\mathrm{Au}$ on $\mathrm{TiO}_{2}$ [13]. Recently, we investigated an innovative modified deposition/precipitation method for the preparation of supported gold nanoparticles [14]. This promising synthetic route involves the use of urea as a basic agent and $\mathrm{NaBH}_{4}$ as a chemical reductant, in contrast to the traditional high-temperature reduction step. A deep spectroscopic investigation combined with other traditional characterisation techniques has deepened our understanding of this modified gold deposition strategy.

In previous works, we applied this technique for the synthesis of $\mathrm{Au} / \mathrm{TiO}_{2}$ samples and tested them for $\mathrm{CO}_{2}$ photoconversion by tuning pressure, temperature, and $\mathrm{pH}[15,16]$. The operating conditions were then selected to maximise the production of gas phase products, i.e., $\mathrm{CH}_{4}+\mathrm{H}_{2}$, with respect to liquid phase organic compounds. However, also in these cases, the adsorption and activation mechanisms remain unclear.

The adsorption process is fundamental for photocatalytic applications, $\mathrm{CO}_{2}$ photo-conversion included. Delavari et al. explored the gas phase reaction using immobilized $\mathrm{TiO}_{2}$ nanoparticles' semiconductor on stainless steel mesh [17]. The Langmuir-Hinshelwood model was applied to the reaction network and revealed that yield rates of products were highly dependent on efficient adsorption of the reactants and desorption of products over the catalyst surface. 
As mentioned, a robust and already deeply investigated modified deposition-precipitation method was adopted in this work for photocatalyst preparation, in order to study the $\mathrm{CO}_{2}$ adsorption pathways and the interaction mechanisms with the common reaction products for different Au loading. The characterization of $\mathrm{TiO}_{2}$ surface and Au nanoparticles was carried out to interpret reactivity and deactivation of photocatalysts for the reduction of $\mathrm{CO}_{2}$ in aqueous medium.

\section{Results and Discussion}

Activity testing of the catalysts revealed a significant productivity for methanol (up to ca. $1.5 \mathrm{~mol} / \mathrm{h} \cdot \mathrm{kg}$ cat, which is a very significant result when compared to the literature) and some methane formed in the gas phase ( $\mathrm{ca} .0 .3 \mathrm{mmol} / \mathrm{h} \cdot \mathrm{kg}_{\text {cat }}$ ) only when using gold-loaded $\mathrm{TiO}_{2}-\mathrm{P} 25$ samples. The productivity of all species increased while increasing the gold content from 0.1 to $0.2 \mathrm{wt}$. \%, then remaining quite constant for a further increase of the metal. $\mathrm{H}_{2}+\mathrm{CO}$ also formed, thanks to a consecutive reaction step of photoreforming, with the highest $\mathrm{H}_{2}$ amount attesting to ca. $18 \mathrm{mmol} / \mathrm{h} \cdot \mathrm{kg}_{\text {cat }}$. The comparison with the bare, unpromoted semiconductor revealed that the main products were $\mathrm{HCHO}$ and $\mathrm{HCOOH}$, with only traces of methanol and no $\mathrm{CH}_{4}$ [18]. Therefore, we undertook an investigation on the role of gold for the activation of $\mathrm{CO}_{2}$ during photoreduction and methanol for the consecutive photoreforming step. The results are reported in the following sections.

\subsection{Morphologic and Electronic Characterization}

Morphologic and electronic characterizations have been widely reported elsewhere [14]. Briefly, high-resolution transmission electron microscopy (HRTEM) and scanning transmission electron microscopy (STEM) have confirmed that adopting the deposition-precipitation method led to very narrow gold particle size distribution fitted by a log-normal curve, with a mean diameter between 3.7 and $4.6 \mathrm{~nm}$. In addition, the nature of the gold species was clarified by X-ray photoelectron microscopy (XPS). The Au4f XPS spectra of $\mathrm{Au} / \mathrm{TiO}_{2}$ samples presented the characteristic $4 \mathrm{f} 7 / 2$ and $\mathrm{Au} 4 \mathrm{f} 5 / 2$ transitions doublet of the two spin-orbit components. Evaluation of the oxidation state of $\mathrm{Au}$, using the binding energy (BE) of the Au 4f7/2 peak, confirmed the well-dispersed and metallic form of gold $\left(\mathrm{Au}^{0}\right)(\mathrm{BE}=$ ca. $83 \mathrm{eV})$ without any detectable $\mathrm{Au}^{\mathrm{n}+}$ species $(\mathrm{BE}=$ ca. $85.5 \mathrm{eV})$.

\subsection{DR UV-Vis Spectra}

For metal nanoparticles of $\mathrm{Au}^{0}, \mathrm{Ag}^{0}$, and $\mathrm{Cu}^{0}$, the plasmon absorption arises from the collective oscillations of the free conduction band electrons that are induced by incident electromagnetic radiation. The study of gold plasmonic bands is an interesting point because their absorption frequency is very sensitive to changes in the environment and material structure $[19,20]$. This investigation was carried out by UV-vis diffuse reflectance absorbance spectroscopy, looking for increased UV absorption with increasing Au content. UV-vis spectra are exhibited in Figure 1. Visible light absorption of $\mathrm{TiO}_{2}$ photocatalysts remarkably enhance with the increase of the gold percentage, due to the surface plasmon resonance (SPR) effect of Au-NPs, indicating that the metallic Au exists in the sample, as already confirmed in XPS analysis and DRIFTS analysis [14]. The visible light absorption of Au-NPs culminates in a broad response, ranging from 450 to $700 \mathrm{~nm}$, which is possibly due to size distribution of Au-NPs. The wavelength at the maximum of the SPR band ( $\lambda$ max) is located at $553 \mathrm{~cm}^{-1}$. For $\mathrm{Au} / \mathrm{TiO}_{2}$ samples, the intensity of absorbance band is related to the size and content of the Au particles. The progressive increase of intensity with metal loading and the equal particle size dimension detected by CO-DRIFTS and microscopies [14] suggests a very specific metal deposition with no alteration of metal size, charge, and morphology. 


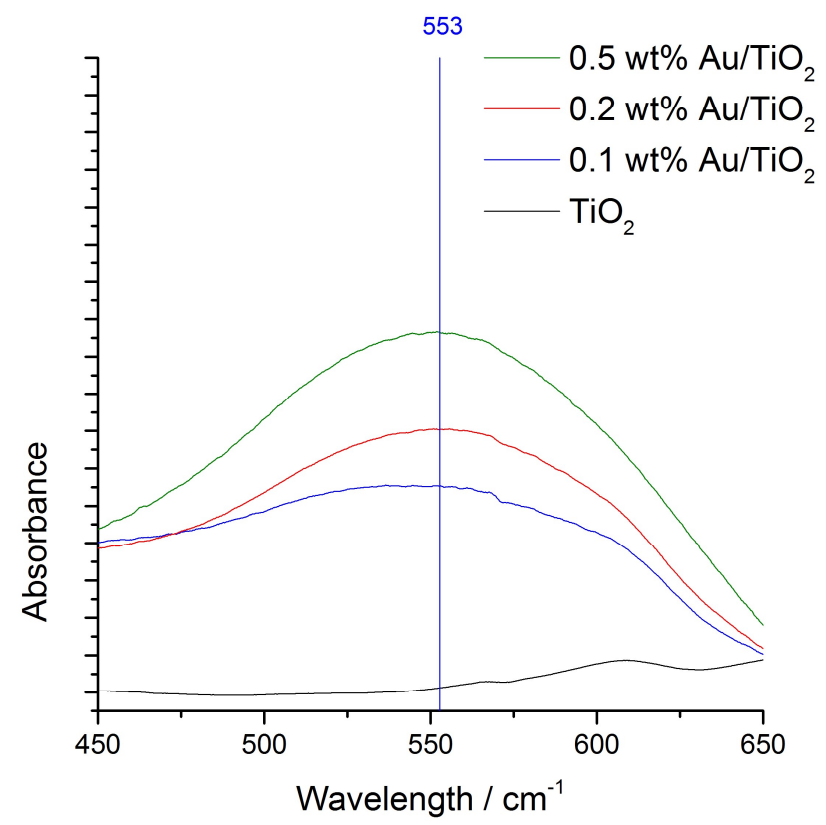

Figure 1. Enlarged UV-vis region of spectra for surface plasmon resonance band of $\mathrm{Au} / \mathrm{TiO}_{2}$ photocatalysts changing the gold loading.

\section{3. $\mathrm{CO}_{2}$-DRIFTS}

The adsorption of $\mathrm{CO}_{2}$ on $\mathrm{TiO}_{2}$ represents the preceding step of the photoreduction reaction, however, its study has been scarcely reported. Few articles have been published considering the nature of $\mathrm{CO}_{2}$ adsorption coupled with advantages and drawbacks from a photocatalytic point of view. This is also true for some of the most studied photocatalysts, such as $\mathrm{TiO}_{2}$ [21-23]. Computational calculations indicated that electron transfer to $\mathrm{CO}_{2}$ can be mediated by surface defects and factors such as phase components (e.g., rutile, anatase) [24].

In this work, DRIFT spectroscopy was applied in the first stage to identify the $\mathrm{CO}_{2}$ adsorption species and reaction intermediates, investigating how the addition of gold nanoparticle influences the process. $\mathrm{CO}_{2}$-DRIFTS spectra are reported in Figure 2. Spectroscopic studies help to unravel mechanism details and changing behavior of the surface catalyst atoms $[25,26]$. Observing the spectra of the 4 different samples, by comparing the relative intensities of the bands (rather than their absolute value, which is not comparable according to the Lambert Beer law for samples different in surface area, density, amount loaded, etc.), it is possible to obtain significant quantitative data on the amount of the adsorbed species.

$\mathrm{CO}_{2}$ adsorption gives rise to several IR bands in the range of $1800-1000 \mathrm{~cm}^{-1}$. Three main peaks at 1312,1416 , and $1577 \mathrm{~cm}^{-1}$ were detected, with a shoulder at higher frequency near $1675 \mathrm{~cm}^{-1}$ for the latter. Moreover, further weaker components are detectable. According to the bibliography, a possible attribution was carried out as reported in Table 1.

One of the main species involved in the $\mathrm{CO}_{2}$ photoreduction process is the carbon dioxide anion radical formed during the reaction mechanism:

$$
\mathrm{CO}_{2}+\mathrm{e}^{-} \rightarrow \mathrm{CO}_{2}^{-} \rightarrow \mathrm{E}_{\text {redox }}=-1.9 \mathrm{eV}(\text { vs. NHE) [8] }
$$

The transfer of an electron from the surface to the adsorbate can also occur without irradiation, simply during the adsorption [27]. Surface $\mathrm{Ti}^{3+}$ centers activate $\mathrm{CO}_{2}$ in this way, forming bands characterized by small $\Delta v$ and placed around 1670 and $1310 \mathrm{~cm}^{-1}$ [27]. 


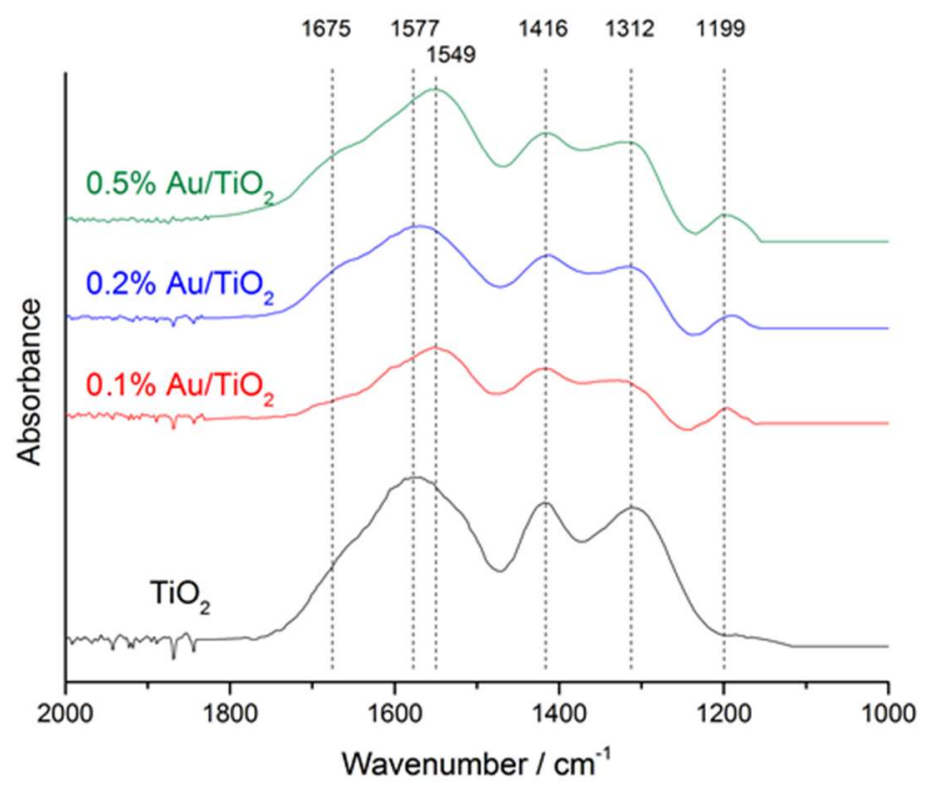

Figure 2. Diffuse reflectance infrared Fourier transform spectroscopy (DRIFTS) spectra of $\mathrm{CO}_{2}$ interaction with gold supported photocatalysts.

Table 1. IR main bands assignment for $\mathrm{Au} / \mathrm{TiO}_{2}$ Samples.

\begin{tabular}{|c|c|c|}
\hline Species & $v\left(\mathrm{~cm}^{-1}\right)$ & Ref. \\
\hline $\mathrm{CO}_{2}$ bent species & 1312,1675 & {$[25]$} \\
\hline Bicarbonate species $\mathrm{HCO}_{3}^{-}$ & $\begin{array}{c}1416, \\
1500-1600\end{array}$ & {$[26,27]$} \\
\hline Bidentate carbonate $\left(\mathrm{b}-\mathrm{CO}_{3}{ }^{2-}\right)$ & $1577-1549$ & {$[28-31]$} \\
\hline
\end{tabular}

The formation and attribution of bidentate carbonate is in accordance with László et al. and their studies on photocatalytic $\mathrm{CO}_{2}$ and $\mathrm{CH}_{4}$ conversion over $\mathrm{Au}$ - and $\mathrm{Rh}$-doped titanate nanotubes [28]. However, any peak of monodentate formate $\left(\mathrm{HCOO}^{\bullet}\right)$ cannot be ruled out in our spectra (bands at 1585 and $1384 \mathrm{~cm}^{-1}$ ). This can be explained considering the reaction mechanism of $\mathrm{CO}_{2}$ photoconversion, because this species is generated only after the reaction between the $\mathrm{CO}^{\bullet-}{ }_{2}$ radical anion and hydrogen ion (Equation (1)), and in dark conditions the anion is not present.

$$
\mathrm{CO}^{\bullet-}{ }_{2}+\mathrm{H}^{+} \rightarrow \mathrm{HCOO}^{\bullet}
$$

Liu and co-workers reported the strong correlation between the reaction mechanism and the carbonate species generated during the initial adsorption in dark conditions [29]. This occurs because of the different behaviors of $\mathrm{CO}^{\bullet-}{ }_{2}$ depending on the carbonate species formed over the surface. In their case, the brookite polymorph revealed a carbonate more reactive than anatase, and the comparison between the dark DRIFTS analysis revealed a stronger presence of $\mathrm{HCO}_{3}{ }^{-}$and $\mathrm{m}-\mathrm{CO}_{3}{ }^{-}$in the case of brookite. However, a new discussion point arose, because in our study analysis was performed on P25, which is a mixture of anatase and rutile (78\% and $22 \%$ respectively). The nature of the present carbonate form is related to the crystalline form, however IR spectra of adsorbed probe molecules supply information mainly from the surface, while XRD gives information mainly from the bulk. Su et al. revealed the b- $\mathrm{CO}_{3}{ }^{2-}$ symmetric mode peak for anatase but not for rutile with a higher peak for surface bicarbonate $\left(\mathrm{HCO}_{3}{ }^{-}\right)$regarding the rutile form [30]. Additionally, the band at $1589 \mathrm{~cm}^{-1}$ is the strongest one when $\mathrm{CO}_{2}$ is adsorbed on anatase, while in the case of rutile, the band at $1416 \mathrm{~cm}^{-1}$ is the strongest one. This is in accordance with our analysis, which represents exactly our mixed situation with commercial P25. 
Another key point is the adsorption competiveness between $\mathrm{CO}_{2}$ and $\mathrm{H}_{2} \mathrm{O}$. The role of water is important either in gas and liquid conditions. For instance, Chen et al. detected a stronger increase of methane yield ( $12 \% \mathrm{CO}_{2}$ conversion) by increasing the $\mathrm{CO}_{2}$ to water ratio using mixed-phase titania nanomaterials [31]. Water is the reductant reagent of the photoreaction. A proper experiment under dry and wet conditions was performed (Figure 3), with the same peak location and band shape of the spectra in Figure 2. A marked increase of the relative intensity of band 1312 and $1675 \mathrm{~cm}^{-1}$ was detected (i.e., peak height subtracted by the baseline of the spectra). This result is crucial: it shows that $\mathrm{H}_{2} \mathrm{O}$ promotes the formation of the $\mathrm{CO}_{2}$ radical anion, with a synergistic effect for $\mathrm{CO}_{2}$ photoreduction.

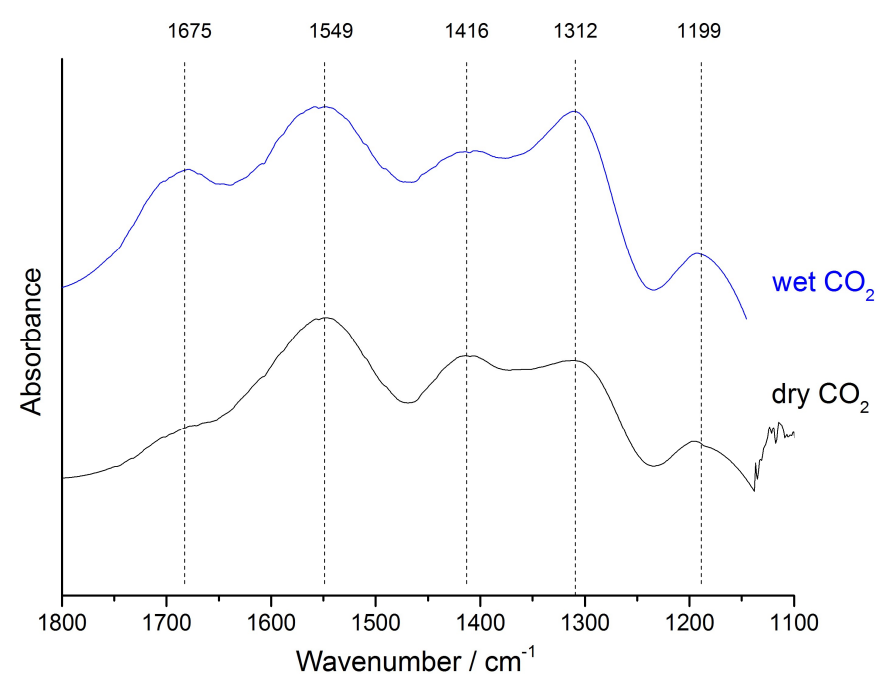

Figure 3. DRIFTS spectra of $\mathrm{CO}_{2}$ and $\mathrm{H}_{2} \mathrm{O}$ interaction on 0.5 wt. $\% \mathrm{Au} / \mathrm{TiO}_{2}: \mathrm{CO}_{2}$ adsorption saturated with water (wet $\mathrm{CO}_{2}$ ) and not $\left(\operatorname{dry} \mathrm{CO}_{2}\right)$.

This analysis also allowed the study of the influence of hydroxyls groups. The identical relative intensities of typical bands associated with hydroxyls in wet and dry conditions confirm that the hydroxylation does not change at all compared to the effect of Figure 3.

The band at $1199 \mathrm{~cm}^{-1}$ was present just for the gold samples, as reported in Figure 2. This aspect is very interesting, because it showssome carbonate formation associated only with gold. The band was associated with a particular bicarbonate formation detected also for other Au-based catalysts in accordance with Neatu et al. [32,33]. The corresponding band is located between 1500-1600 $\mathrm{cm}^{-1}$, so not clearly detectable, because of the overlapping. This can be confirmed by observing the comparison of peak relative intensities (i.e., peak height subtracted by the baseline of the spectra). In particular, the intensity of the peak at $1549-1579 \mathrm{~cm}^{-1}$ is the highest in the case of bare $\mathrm{TiO}_{2}$, with a relative decrease of $20-60 \%$ for the gold samples. The absolute value of this decrease is comparable with the peak intensities of the bands at $1199 \mathrm{~cm}^{-1}$ for the gold samples.

The addition of gold provides evidence of a lower formation of bidentate carbonates, favouring higher concentration of surface bicarbonate species. The intensity of the latter band increases in wet conditions with respect to dry $\mathrm{CO}_{2}$. This can suggest a possible promoting effect of gold, which plays a role in the activation of surface $\mathrm{OH}$ in $\mathrm{CO}_{2}$ adsorption.

The intensity of the band at $1199 \mathrm{~cm}^{-1}$ increases in wet conditions with respect to dry $\mathrm{CO}_{2}$.

\subsection{DRIFTS of Adsorbed Methanol and Ethanol}

Another key point is the evaluation of products and reagents during the photoreactions. Methanol is one of the main products of the process $[34,35]$ and is also the key compound for the subsequent photoreforming step [5]. With the aim of identifying surface species that were formed during methanol adsorption and that can be considered for the mechanism assumptions proposed in literature, several 
DRIFTS analyses using methanol as probe molecule were carried out. The spectra are shown in Figure 4A,B.

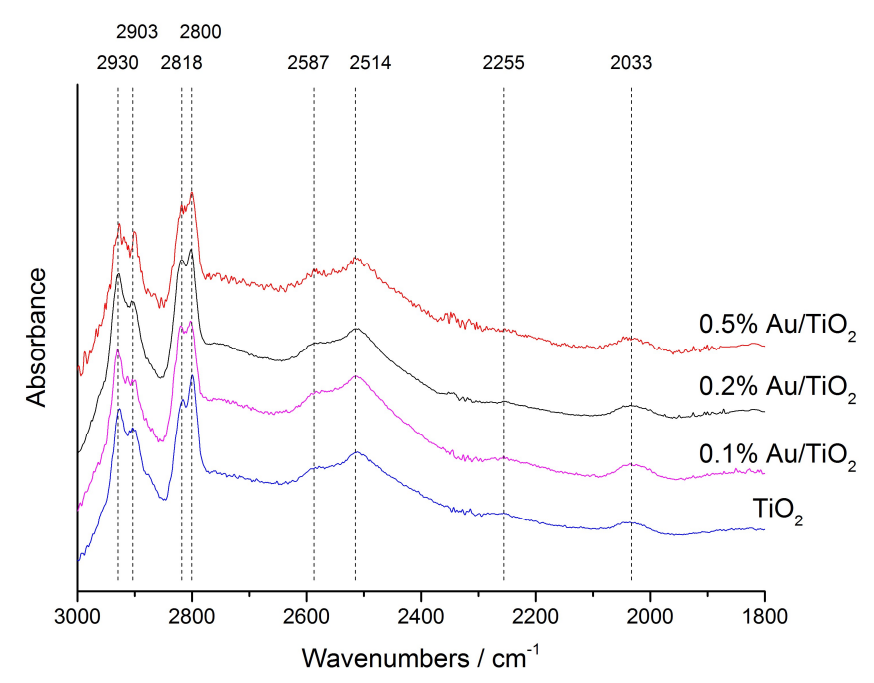

(A)

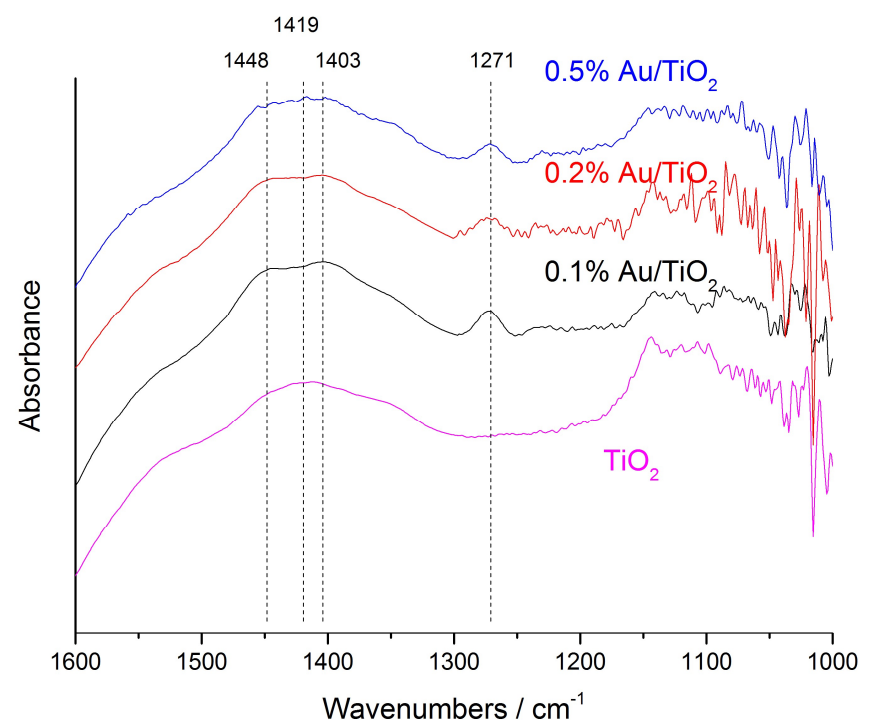

(B)

Figure 4. (A) DRIFTS spectra recorded as a $\mathrm{TiO}_{2}$-supported gold sample was treated in flowing mixtures of methanol and $\mathrm{N}_{2}$ in $3000-1800 \mathrm{~cm}^{-1}$ spectral region. (B) DRIFTS spectra recorded as a $\mathrm{TiO}_{2}$-supported gold sample was treated in flowing mixtures of methanol and $\mathrm{N}_{2}$ in $1600-1000 \mathrm{~cm}^{-1}$ spectral region (down).

In addition to the $\mathrm{C}-\mathrm{H}$ stretching bands in the region between $2800-3000 \mathrm{~cm}^{-1}$, characteristic alkoxy surface species $-\mathrm{OCH}_{3}$ were detected in not well-resolved spectral region around $1100 \mathrm{~cm}^{-1}$ [36-38]. An important role of the methoxy species was attributed by Greaves et al. [39], assuming their direct involvement in the photoreforming mechanism, especially in the presence of gold. The kinetic mechanism proposed considers the methanol adsorption at free sites on gold nanoparticles and subsequent formation of a methoxy intermediate, which is stable in the absence of light and blocks the reaction. In the presence of light, the photo-generation of holes induces the formation of the high oxidative hydroxyl radical, which reacts with the methoxy species and forms $\mathrm{CO}_{2}$ and $\mathrm{H}_{2} \mathrm{O}$. The adsorption mechanism on $\mathrm{Au} / \mathrm{TiO}_{2}$ proceeds accordingly with the following mechanisms [39]: 
(a) $\mathrm{CH}_{3} \mathrm{OH} \rightarrow \mathrm{CH}_{3} \mathrm{OH}^{*}$

(b) $\mathrm{CH}_{3} \mathrm{OH}+\mathrm{O}^{2-*} \rightarrow \mathrm{CH}_{3} \mathrm{O}^{-*}+\mathrm{OH}^{-*}$

(c) $\mathrm{CH}_{3} \mathrm{OH}^{*}+\mathrm{OH}^{-*} \rightarrow \mathrm{CH}_{3} \mathrm{O}^{-*}+\mathrm{H}_{2} \mathrm{O}+\mathrm{V}_{\mathrm{o}}{ }^{2-}$

Where * denotes the species adsorbed on the $\mathrm{TiO}_{2}$ surface and $\mathrm{V}_{\mathrm{o}}{ }^{2-}$ anion vacancies. In Figure 4 the presence of the bands at 2930 and $2818 \mathrm{~cm}^{-1}$ indicates that methoxy species are formed according to steps (b,c) above. The bands at 2930 and $2800 \mathrm{~cm}^{-1}$ correspond to the couple of $v_{\mathrm{sym}} \mathrm{CH}_{3}$ modes [38].

Therefore, our results confirmed that the band at $2930 \mathrm{~cm}^{-1}$ is relative to the methoxy species bonded to $\mathrm{Ti}^{4+}$ sites, while the presence of gold does not influence the nature of the adsorption process. However, the relative intensity of the peak at $2818 \mathrm{~cm}^{-1}$ is significantly lower in bare P25 compared to samples with gold, indicating a higher amount of $\mathrm{V}_{\mathrm{o}}{ }^{2-}$ anion vacancies in presence of gold particles.

This aspect can be associated with the other big difference comparing the gold samples with the bare one (Table 2): the two additional peaks for the bands at $1448 \mathrm{~cm}^{-1}$ and $1271 \mathrm{~cm}^{-1}$. A spectroscopic investigation by Martinez et al. performed using methanol and $\mathrm{TiO}_{2}$-supported gold materials revealed the possible influence of metal loading and deposition method of gold [40]. They did not conclude that there is any influence of gold when comparing the spectra during the methanol adsorption. However, a very high metal loading was used ( $5 \mathrm{wt}$. \%) and a deposition method involving $\mathrm{NaBH}_{4}$ was carried out. By contrast, Calzada et al., studying gold samples prepared by deposition-precipitation method at low loading, like in our case, reported differences comparing the metal containing sample and the bare support [41], revealing the critical influence of gold present during methanol adsorption. So, according to K. Kähler at al., the band at $1271 \mathrm{~cm}^{-1}$, associated with the band at $1448 \mathrm{~cm}^{-1}$, was attributed to a carbonate formed on Au metal nanoparticles [42].

Table 2. IR main bands assignment for $\mathrm{Au} / \mathrm{TiO}_{2}$ Samples.

\begin{tabular}{ccc}
\hline Surface Species & Frequency $\left.\mathbf{( c m}^{\mathbf{- 1}}\right)$ & Ref. \\
\hline$v_{\text {sym }} \mathrm{CH}_{3}$ modes of Methoxy on top on $\mathrm{Ti}^{\mathrm{n+}}$ & $2930-2800$ & This work, [36-38,43] \\
\hline Carbonates due to $\mathrm{Au}$ & 1448,1271 & This work, [42] \\
\hline
\end{tabular}

A less polar and hydrophilic alcohol, such as ethanol, was used for a comparison with methanol DRIFT spectra. The results are shown in Figure 5.

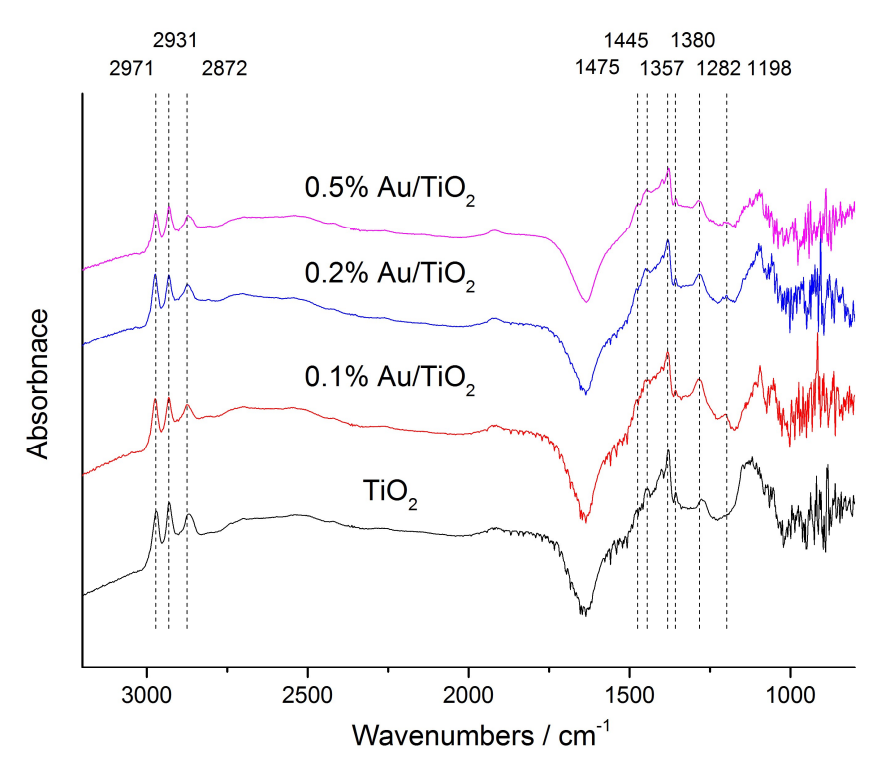

Figure 5. DRIFTS spectra recorded as a $\mathrm{TiO}_{2}$-supported gold sample was sequentially treated in flowing mixtures of ethanol and $\mathrm{N}_{2}$. 
According to Gong et al. [44], the formation of the aldehyde is one of the first steps for ethanol decomposition. Alkoxy groups form in dark conditions upon ethanol adsorption. The identification of these alkoxy groups and their evolution on different oxidic surfaces, in our case $\mathrm{TiO}_{2}$ and $\mathrm{Au} / \mathrm{TiO}_{2}$, is a key point.

$$
\mathrm{CH}_{3} \mathrm{CH}_{2} \mathrm{OH} \rightarrow \mathrm{CH}_{3} \mathrm{CH}_{2} \mathrm{O}-\mathrm{Ti}^{*}+\mathrm{OH}^{*}
$$

Formal charges are omitted for clarity. As in the case of methanol, a new band associated with carbonate on Au nanoparticles at $1198 \mathrm{~cm}^{-1}$ was present.

\subsection{DRIFTS-OH Region}

Surface $\mathrm{OH}$ groups can directly influence photoactivity performance. Indeed, $\mathrm{OH}$ groups are efficient carrier traps for the holes generated in the lattice by the absorption of light. The mechanism proposed is the following [45-47]:

$\mathrm{Ti}^{\mathrm{IV}}-\mathrm{OH}^{-}+\mathrm{h}^{+} \rightarrow \mathrm{Ti}^{\mathrm{IV}}-\mathrm{OH}$.

$\mathrm{Ti}^{\mathrm{IV}}-\mathrm{H}_{2} \mathrm{O}+\mathrm{h}^{+} \rightarrow \mathrm{Ti}^{\mathrm{IV}}-\mathrm{OH} \cdot+\mathrm{H}^{+}$

In addition to the high oxidation potential, these radicals act as adsorption sites for many molecules, and therefore are fundamental for the initial $\mathrm{CO}_{2}$ photoreduction process (high oxidation of the hole scavenger) and photoreforming of organic products.

DRIFT spectra under $\mathrm{N}_{2}$ atmosphere were performed in order to study of surface hydroxyl groups of titania and the influence of metal loading. Two characteristic bands at 3693 and $3632 \mathrm{~cm}^{-1}$ were detected in the $\mathrm{OH}$ spectral region between $3400-4000 \mathrm{~cm}^{-1}$. The higher frequency band is ascribed to terminal hydroxyl groups coordinated to $\mathrm{Ti}^{4+}$ sites, which are responsible for photocatalytic activity, while the lower is related to the bridged hydroxyl species [45,47].

No band at $3400 \mathrm{~cm}^{-1}$ was detected because of the absence of water in the nitrogen flow (this band is usually reported and attributed to hydrogen-bonded water in interaction with surface hydroxyl groups) [47,48]. A slight attenuation of the higher band intensity was observed for the sample with the highest Au loading. This effect was reported to be more marked by Orlov et al. and was attributed to the partial elimination of hydroxyl groups [48]. However, their study was performed comparing a very different metal loading (from 0.42 to $5.58 \%$ ).

The experimental analysis confirmed the low influence for the surface hydroxylation of such a percentage in weight of gold on high surface area titania.

\subsection{XPS-Fresh Catalyst (O Region, Ti Region)}

In order to investigate how the surface hydroxyl species change after gold deposition treatment and the related photoactivity of the materials, X-ray photoelectron spectroscopy was adopted as complementary investigation technique. XPS gives information on valence of elements on and near the surface of photocatalysts. As shown in Table 3, OH/lattice oxygen ratios are quite similar, although a slight decrease of the value with increasing the gold loading reveals less $\mathrm{OH}$ groups.

Table 3. XPS Analysis of the surface composition of fresh samples.

\begin{tabular}{ccccccc}
\hline Sample & Au $4 \mathbf{f}$ & O 1s (Lattice) & O 1s (OH) & Ti 2p & OH/Lattice O & Ti/O (Lattice) Ratio \\
\hline $0.1 \% \mathrm{Au} / \mathrm{TiO}_{2}$ & 0.04 & 36.49 & 5.11 & 18.61 & 0.14 & 0.51 \\
$0.2 \% \mathrm{Au} / \mathrm{TiO}_{2}$ & 0.05 & 35.22 & 4.69 & 17.71 & 0.13 & 0.50 \\
$0.5 \% \mathrm{Au} / \mathrm{TiO}_{2}$ & 0.09 & 36.87 & 4.38 & 18.51 & 0.12 & 0.50 \\
\hline
\end{tabular}

The nature of the negative charge on gold is closely related to support [49], in particular regarding the charge transfer between gold particles and $\mathrm{M}^{3+}$ cations of the support lattice. Many studies have pointed out that defect sites (e.g., oxygen vacancies) might play an important role in charge transfer for the formation of negatively charged gold. 
The $\mathrm{Au} 4 \mathrm{f}$ XPS spectra of $\mathrm{Au} / \mathrm{TiO}_{2}$ samples are shown in Figure 6, where the characteristic doublet of the two spin-orbit components are visible ( $4 f_{7 / 2}$ and $A u 4 f_{5 / 2}$ transitions). The oxidation state of $A u$ at the surface of the catalyst was evaluated by analysing the values of binding energy (BE), referring to the $\mathrm{Au} 4 \mathrm{f}_{7 / 2}$ peak.

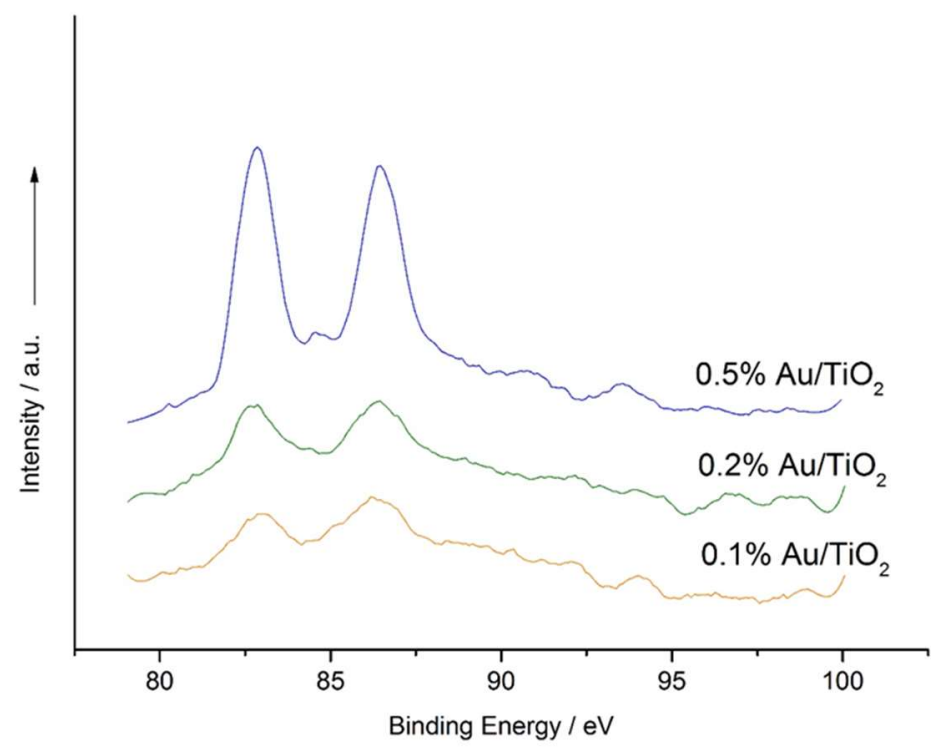

Figure 6. XPS spectra of $\mathrm{Au} 4 \mathrm{f}$ region for 0.1 wt. \%, 0.2 wt. \% and 0.5 wt. \% $\mathrm{Au} / \mathrm{TiO}_{2}$ samples.

\subsection{Spent Photocatalyst Characterization}

Deactivation is a general problem in heterogeneous processes, due to the accumulation of intermediate products or products on the $\mathrm{TiO}_{2}$ surface [50]. The deactivation can be reversible or irreversible. Blount et al. investigated the photocatalytic oxidation of toluene in gas phase using $\mathrm{Pt} / \mathrm{TiO}_{2}-\mathrm{P} 25$ and detected a deactivation, due to the less reactive intermediate produced during the reaction, such as benzoic acid [51]. Regarding $\mathrm{CO}_{2}$ photoreduction, very few papers can be found talking about deactivation phenomena. Deactivation from carbonaceous species formed during the photocatalytic reduction of $\mathrm{CO}_{2}$ with water in gas phase was studied by Uner and co-workers using $\mathrm{Pt} / \mathrm{TiO}_{2}$ photo-catalysts [52]. Unfortunately, the carbon deposition over the photocatalyst surface was only identified by evaluating the methane formation in dark conditions in presence of hydrogen. Another critical intermediate or product, depending on the goal of the process, is carbon monoxide, because its presence can lead to a marked deactivation of the catalyst if the material composition is not properly tuned [53].

The photoactivity tests for these photocatalysts and the relative discussions were reported elsewhere [15], because in this work the focus was on bringing a contribution about the mechanisms and relevance of reagent and product adsorption/interactions with gold-loaded titania. Briefly, tests were carried out at 6 bar, basic $\mathrm{pH}(12), 80^{\circ} \mathrm{C}$, and a time reaction of $70-90 \mathrm{~h}$ [15]. To better clarify the critical aspects involved in the photoreaction mechanism, post-catalytic measurements were performed in order to investigate the variation occurred in the catalyst during the photoreaction. For instance, the formation of the strong reductant radical anion $\mathrm{CO}_{2} \cdot{ }^{-}$can change the gold oxidation state during the test, representing a critical aspect because of the changing of the band gap or photoactivity efficiency. Although this aspect was detected for sulfide-based semiconductors during $\mathrm{CO}_{2}$ photoreduction [54], its presence using $\mathrm{TiO}_{2}$ seems unlikely due to the high resistance of the titania below UV irradiation, especially in the wavelength range used in this work.

The photocorrosion of the materials was found particularly relevant for reactions carried out in water and when the metal is deposited on its surface. The critical point is the metal leaching phenomenon involving the gradual deactivation of the catalyst, which can occur due to its continuous 
metal oxidation/reduction cycles [6]. In addition the accumulation of the photo-generated holes in the valence band can be a photocorrosion source if a proper amount of hole scavenger is not used [55].

XPS was used to investigate the oxidation state of gold and carbon on the surface of the spent catalysts (Table 4). This aspect of photocorrosion was studied on the samples used for the longer kinetic tests $(92 \mathrm{~h})$, in order to stress the critical conditions for the photocatalyst.

Table 4. XPS binding energy of $\mathrm{Au}_{4} \mathrm{f}_{7 / 2}$ region data and $\mathrm{C}$ atomic percentage for gold based catalysts before and after the photoactivity tests.

\begin{tabular}{ccccc}
\hline Sample & $\mathbf{A u} \mathbf{4 f}_{\mathbf{7 / 2}}$ BE Fresh (eV) & $\mathbf{A u} \mathbf{4 f}_{\mathbf{7 / 2}}$ BE Spent (eV) & $\mathbf{C}$ 1s, \%at Conc Fresh & C 1s, \%at Conc Spent \\
\hline $\mathbf{0 . 1}$ wt. \% Au/TiO & 83.6 & 83.0 & 39.59 & 36.14 \\
$\mathbf{0 . 2}$ wt. \% Au/TiO & 83.6 & 83.0 & 42.09 & 36.38 \\
$\mathbf{0 . 5}$ wt. \% Au/TiO & 83.6 & 83.0 & 39.99 & 41.93 \\
\hline
\end{tabular}

XPS Au band analysis on a spent sample revealed the presence of metallic gold, and the absence of any charge modification, as proposed by other works on other photocatalytic conditions and processes [56].

The quantity of the surface carbon detected by XPS was very similar, without denoting any significant carbon deposition during the photoactivity tests. Therefore, in light of these results, it would be expected to obtain the same IR spectra after $\mathrm{CO}$ adsorption on the fresh and spent samples. For this reason, the charge and the dispersion of the gold nanoparticles were probed using carbon monoxide, combined with DRIFT spectroscopy (Figure 7). In a detailed previous article, the surface of these fresh materials was studied in depth using CO-DRIFTS for the CO oxidation reaction [14]. For all the $\mathrm{Au} / \mathrm{TiO}_{2}$ fresh samples, the presence of $\mathrm{CO}$ gave rise to one or two IR bands in the $\mathrm{CO}$ carbonyl spectral region (1950-2150 $\left.\mathrm{cm}^{-1}\right)$. The highest frequency IR band $\left(2106 \mathrm{~cm}^{-1}\right)$ was attributed to linearly adsorbed CO on metallic gold, while the broad and asymmetric band at lower frequencies, with the maximum located at $2072 \mathrm{~cm}^{-1}$, was deconvoluted on the basis of a Gaussian model and the several overlapping peaks were attributed to the linear, multisite, and bridged $\mathrm{CO}$ on $\mathrm{Au}^{\delta-}$.

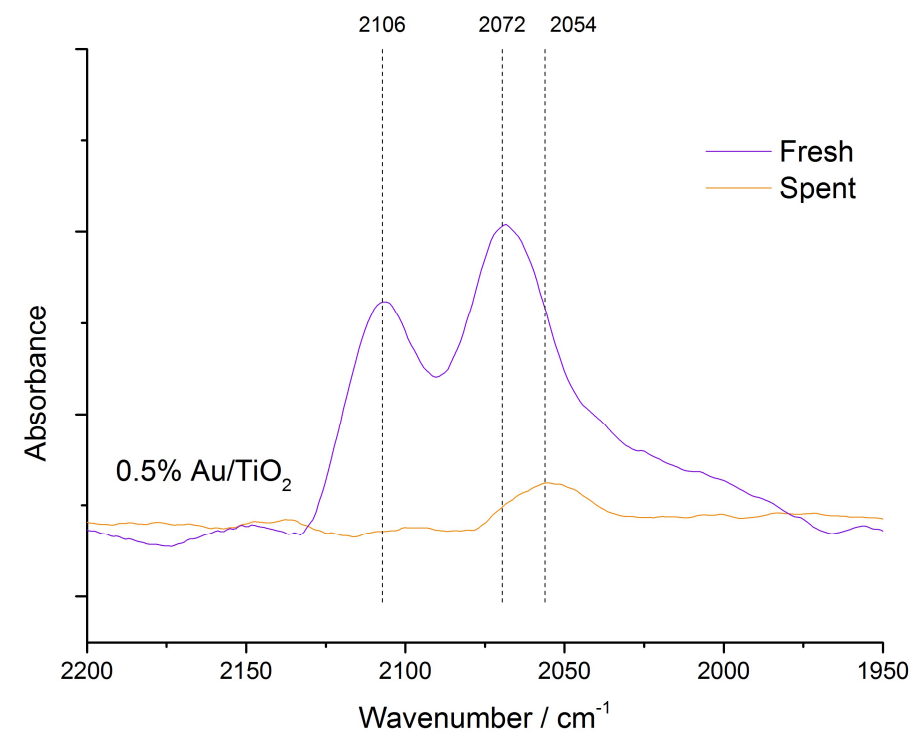

Figure 7. CO-DRIFT spectra over 0.5 wt. $\% \mathrm{Au} / \mathrm{TiO}_{2}$ samples before and after the photocatalytic $\mathrm{CO}_{2}$ reduction.

DRIFT analysis without probe molecules was then carried out on the spent samples in order to check the presence of $\mathrm{CO}$, which is sometimes considered one of the deactivating compounds. The spectra, after the subtraction of the fresh analogues, revealed the formation of several species in the carbonate region, as shown in Figure 8. All spent spectra did not reveal CO chemisorbed or 
physisorbed (peaks usually ascribed to the region 2017-1970 $\mathrm{cm}^{-1}$ ) [37], leading to the conclusion that in liquid phase this deactivation mechanism is minor with respect the gas phase process. The $\mathrm{CO}$ generation occurs mainly due to the Ti centers of the oxidic support [57], because the other possible path (direct photolysis of $\mathrm{CO}_{2}$ ) is very unlikely out of the deep UV irradiation conditions [6]. Another point supporting this result is the fact that $\mathrm{CO}$ is bound much more weakly to the Au surface due to the low energy of $d$ orbitals in Au with respect other metals such as Pd [39].

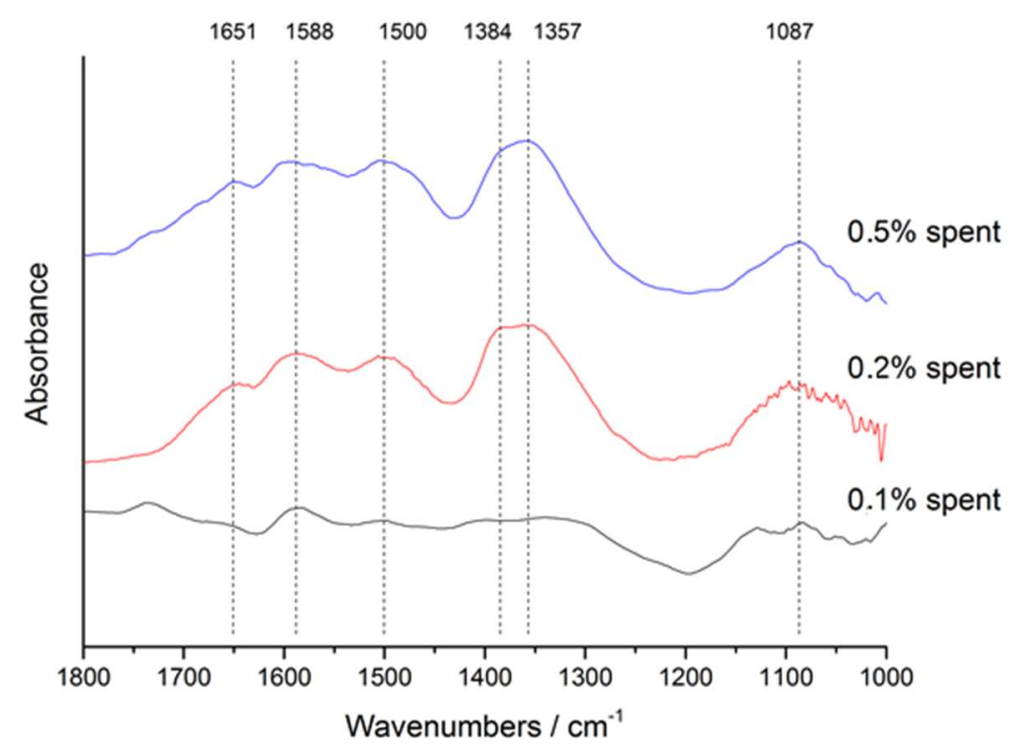

Figure 8. Carbonate IR region obtained after the subtraction of DRIFTS spectra of fresh samples to spent samples.

\section{Materials and Methods}

\subsection{Preparation of $\mathrm{Au} / \mathrm{TiO}_{2}$}

The deposition-precipitation method was used to load Au nanoparticles (NPs) with urea and a chemical reductant (DP-UC). $1 \mathrm{~g}$ of $\mathrm{TiO}_{2}$ (Evonik, Essen, Germany, $\mathrm{TiO}_{2} \mathrm{P} 25, \mathrm{SA} 50 \mathrm{~m}^{2} \mathrm{~g}^{-1}$ ) was suspended in distilled water (100 mL) and added to $5 \mathrm{~g}$ of urea (Aldrich, Saint Louis (MO, US, >99\%). A solution of $\mathrm{NaAuCl}_{4} \cdot 2 \mathrm{H}_{2} \mathrm{O}$ (Aldrich, $99.99 \%$ ) was added and the mixture was stirred for $4 \mathrm{~h}$ at $353 \mathrm{~K}$. The catalyst was filtered and repeatedly washed with water. The material was again suspended in distilled water and added at room temperature with a $0.1 \mathrm{M}$ solution of $\mathrm{NaBH}_{4}$ (Fluka, $>96 \%$ ) so to have $\mathrm{NaBH}_{4} / \mathrm{Au}=4 \mathrm{~mol} / \mathrm{mol}$ [58]. The sample was filtered, washed, and dried at $373 \mathrm{~K}$ for $4 \mathrm{~h}$. Au loading was analysed by Atomic Absorption Spectroscopy (AAS) analysis of the filtrate (Perkin Elmer, Monza (MB), Italy, mod. 3100), retrieving the nominal composition. $\mathrm{Au} / \mathrm{TiO}_{2}$ catalysts with the following composition were prepared: 0.1 wt. \%, 0.2 wt. $\%, 0.5$ wt. $\% \mathrm{Au} / \mathrm{TiO}_{2}$. Bare P25 was used as a reference.

\subsection{Characterization}

Diffuse reflectance infrared Fourier transform spectroscopy (DRIFTS) was carried out by means of a Bruker ( Coventry, CV4 9GH, UK) Tensor 27 spectrometer fitted with a HgCdTe (MCT) detector, a Harrick Praying Mantis HVC-DRP-4 cell equipped with two ZnSe windows, and operated with OPUS software. The DRIFTS cell was equipped with gas inlet and outlet and heating and cooling devices. $40 \mathrm{~cm}^{3} \mathrm{~min}^{-1}$ of a $5 \% \mathrm{CO} / \mathrm{N}_{2}$ gas mixture were fed through mass-flow controllers. Each spectrum is the average of 64 scans collected with a spectral resolution of $2 \mathrm{~cm}^{-1}$. When $\mathrm{CO}_{2}$ was used as a probe, a flow of $6 \mathrm{~cm}^{3} \mathrm{~min}^{-1}$ of a $30 \% \mathrm{CO}_{2}$ in $\mathrm{N}_{2}$ was fed in order to have the best comparable results. Each spectrum is the average of 64 scans collected with a spectral resolution of $2 \mathrm{~cm}^{-1}$. 
The ZnSe windows used cut off the spectrum below $650 \mathrm{~cm}^{-1}$, therefore this region was not included in the discussion. The results are reported as absorbance, so in the reported spectra a positive increase of peak intensity indicates an increase of the amount of that species, whereas a negative one shows loss of moieties associated with that particular vibrational mode. All samples were ground before the analysis. The spectra are obtained after subtraction of reference background recorded under $\mathrm{N}_{2}$ flow after heating the sample at $393 \mathrm{~K}$ for $30 \mathrm{~min}$.

Diffuse Reflectance (DR) UV-Vis spectra were obtained by means of a Varian (Palo Alto (CA), US) Cary 4000 spectrophotometer including a Harrick Praying Mantis HVC-DRP-4 cell. The catalyst was placed in the cell and spectra were recorded under $\mathrm{N}_{2}$ atmosphere, air, $1 \% \mathrm{CO} / \mathrm{N}_{2}$ or $1 \% \mathrm{CO} /$ air $\left(50 \mathrm{~mL} \mathrm{~min}^{-1}\right)$.

X-ray photoelectron spectroscopy (XPS) was carried out with a Kratos (Manchester, M17 1GP, UK) Axis Ultra-DLD instrument with a monochromatic $\mathrm{Al} \mathrm{K}_{\alpha} \mathrm{X}$-ray source operating at a power of $144 \mathrm{~W}(12 \mathrm{~mA} \times 12 \mathrm{kV})$ power. High resolution and survey scans were performed at pass energies of 40 and $160 \mathrm{eV}$, respectively. Spectra were calibrated to the $\mathrm{C}(1 \mathrm{~s})$ signal at $284.8 \mathrm{eV}$ and quantified using CasaXPS and a modified Wagner sensitivity factors supplied by the manufacturer.

\section{Conclusions}

The characterization of $\mathrm{TiO}_{2}$ surface and Au nanoparticles was carried out to interpret reactivity and deactivation of photocatalysts for the reduction of $\mathrm{CO}_{2}$ in aqueous medium. Different modes of $\mathrm{CO}_{2}$ surface adsorption have been observed upon Au loading. This can promote the activation of $\mathrm{CO}_{2}$ during the photocatalytic process. Due to the formation of different reduction products towards methanol, the latter was also tested for surface adsorption. This information is important for interpreting the consecutive photoreforming step. The deposition of Au nanoparticles induced a significant plasmon resonance band, whose intensity increased proportionally with metal loading. $\mathrm{CO}_{2}$ adsorbed in different coexisting forms on catalyst surface, i.e., $\mathrm{CO}_{2}$, bicarbonate and carbonate species. The formation of the $\mathrm{CO}_{2}$ radical anion was crucially improved by the presence of water. The presence of gold gave rise to a specific $\mathrm{CO}_{2}$ adsorption feature, which likely is correlated to an activated state, based on the higher photocatalytic efficiency observed for these samples.

Methanol adsorption mainly occurs over $\mathrm{TiO}_{2}$ sites, forming methoxy-species, which can be further oxidised in the consecutive photoreforming step. Carbonates over Au particles were contemporarily detected.

The characterisation of the spent catalysts revealed the good stability of these samples, which did not undergo any significant change of gold loading or oxidation state, nor important variation of the amount of $C$ adsorbed on the surface (surface saturation).

Author Contributions: M.C., E.B. and D.J.M.: collection of experimental data for catalysts characterization; M.C.: writing-original draft preparation; A.V.: catalysts preparation; L.P., N.D.: supervision; I.R. and G.R.: writing - review and editing, funding acquisition, supervision, project administration.

Funding: The financial contribution of MIUR through the PRIN2015 grant (20153T4REF) is gratefully acknowledged (G. Ramis and I. Rossetti). I. Rossetti and E. Bahadori are grateful to Fondazione Cariplo and Regione Lombardia for financial support through the grant 2016-0858-Up-Unconventional Photoreactors.

Acknowledgments: We would like to acknowledge the Erasmus Placement program for the scholarship attributed to M. Compagnoni supporting the internship at the Cardiff Catalysis Institute (Cardiff University).

Conflicts of Interest: The authors declare no conflicts of interest.

\section{References}

1. Olivo, A.; Trevisan, V.; Ghedini, E.; Pinna, F.; Bianchi, C.L.; Naldoni, A.; Cruciani, G.; Signoretto, M. CO 2 photoreduction with water: Catalyst and process investigation. J. $\mathrm{CO}_{2}$ Util. 2015, 12, 86-94. [CrossRef]

2. Liu, L.; Jiang, Y.; Zhao, H.; Chen, J.; Cheng, J.; Yang, K.; Li, Y. Engineering coexposed [001] and [101] facets in oxygen-deficent $\mathrm{TiO}_{2}$ nanocrystals for enhanced $\mathrm{CO}_{2}$ photoreduction under visble light. ACS Catal. 2016, 6, 1097-1108. [CrossRef] 
3. Tahir, M.; Tahir, B.; Amin, N.A.S. Gold-nanoparticle-modified $\mathrm{TiO}_{2}$ nanowires for plasmon enhanced photocatalytic $\mathrm{CO}_{2}$ reduction with $\mathrm{H}_{2}$ under visible light irradiation. Appl. Surf. Sci. 2015, 356, 1289-1299. [CrossRef]

4. Li, G.; Ciston, S.; Saponjic, Z.V.; Chen, L.; Dimitrijevic, N.M.; Rajh, T.; Gray, K.A. Synthesizing mixed-phase $\mathrm{TiO}_{2}$ nanocomposites using a hydrothermal method for photo-oxidation and photoreduction applications. J. Catal. 2008, 253, 105-110. [CrossRef]

5. Galli, F.; Compagnoni, M.; Vitali, D.; Pirola, C.; Bianchi, C.L.; Villa, A.; Prati, L.; Rossetti, I. CO $\mathrm{CO}_{2}$ photoreduction at high pressure to both gas and liquid products over titanium dioxide. Appl. Catal. B Environ. 2017, 200, 386-391. [CrossRef]

6. Corma, A.; Garcia, H. Photocatalytic reduction of $\mathrm{CO}_{2}$ for fuel production: Possibilities and challenges. J. Catalysis 2013, 308, 168-175. [CrossRef]

7. Ohtani, B. Photocatalysis A to Z-What we know and what we do not know in a scientific sense. J. Photochem. Photobiol. C Photochem. Rev. 2010, 11, 157-178. [CrossRef]

8. Habisreutinger, S.N.; Schmidt-Mende, L.; Stolarczyk, J.K. Photocatalytic Reduction of $\mathrm{CO}_{2}$ on $\mathrm{TiO}_{2}$ and Other Semiconductors. Angew. Chem. Int. Ed. 2013, 52, 7372-7408. [CrossRef] [PubMed]

9. Low, J.; Qiu, S.; Xu, D.; Jiang, C.; Cheng, B. Direct evidence and enhancement of surface plasmon resonance effect on Ag-loaded $\mathrm{TiO}_{2}$ nanotube arrays for photocatalytic $\mathrm{CO}_{2}$ reduction. Appl. Surf. Sci. 2018, 434, 423-432. [CrossRef]

10. Mele, G.; Annese, C.; de Riccardis, A.; Fusco, C.; Palmisano, L.; Vasapollo, G.; D'Accolti, L. Turning lipophilic phthalocyanines $/ \mathrm{TiO}_{2}$ composites into efficient photocatalysts for the conversion of $\mathrm{CO}_{2}$ into formic acid under UV-vis light irradiation. Appl. Catal. A General 2014, 481, 169-172. [CrossRef]

11. Prati, L.; Villa, A. The Art of Manufacturing Gold Catalysts. Catalysts 2012, 2, 24-37. [CrossRef]

12. Dimitratos, N.; Villa, A.; Bianchi, C.L.; Prati, L.; Makkee, M. Gold on titania: Effect of preparation method in the liquid phase oxidation. Appl. Catal. A Gen. 2006, 311, 185-192. [CrossRef]

13. Villa, A.; Ferri, D.; Campisi, S.; Chan-Thaw, C.E.; Lu, Y.; Kröcher, O.; Prati, L. Operando Attenuated Total Reflectance FTIR Spectroscopy: Studies on the Different Selectivity Observed in Benzyl Alcohol Oxidation. Chem CatChem 2015, 7, 2534-2541. [CrossRef]

14. Compagnoni, M.; Kondrat, S.A.; Chan-Thaw, C.E.E.; Morgan, D.J.; Wang, D.; Prati, L.; Dimitratos, N.; Rossetti, I. Spectroscopic Investigation of Titania-Supported Gold Nanoparticles Prepared by a Modified Deposition/Precipitation Method for the Oxidation of CO. ChemCatChem 2016, 8, 12. [CrossRef]

15. Rossetti, I.; Villa, A.; Compagnoni, M.; Prati, L.; Ramis, G.; Pirola, C.; Bianchi, C.L.; Wang, W.; Wang, D. $\mathrm{CO}_{2}$ photoconversion to fuels under high pressure: effect of $\mathrm{TiO}_{2}$ phase and of unconventional reaction conditions. Catal. Sci. Technol. 2015, 5, 4481-4487. [CrossRef]

16. Rossetti, I.; Villa, A.; Pirola, C.; Prati, L.; Ramis, G. A novel high-pressure photoreactor for $\mathrm{CO}_{2}$ photoconversion to fuels. RSC Adv. 2014, 4, 28883-28885. [CrossRef]

17. Delavari, S.; Amin, N.A.S. An optimization approach for long term investments planning in energy. Appl. Energy 2014, 162, 1171-1185. [CrossRef]

18. Compagnoni, M.; Bahdori, E.; Tripodi, A.; Villa, A.; Pirola, C.; Prati, L.; Ramis, G.; Dimitratos, N.; Wang, D.; Rossetti, I. High Pressure $\mathrm{CO}_{2}$ Photoreduction using $\mathrm{Au} / \mathrm{TiO}_{2}$ : unravelling the effect of the co-catalyst and of the titania polymorph. J. Mater. Chem. A. submitted.

19. Yuzawa, H.; Yoshida, T.; Yoshida, H. Gold nanoparticles on titanium oxide effective for photocatalytic hydrogen formation under visible light. Appl. Catal. B Environ. 2012, 115-116, 294-302. [CrossRef]

20. Lari, G.M.; Nowicka, E.; Morgan, D.J.; Kondrat, S.a.; Hutchings, G. The use of carbon monoxide as a probe molecule in spectroscopic studies for determination of exposed gold sites on $\mathrm{TiO}_{2}$. J. Phys. Chem. Chem. Phys. 2015, 17, 23236-23244. [CrossRef]

21. Liu, G.; Hoivik, N.; Wang, K.; Jakobsen, H. Engineering $\mathrm{TiO}_{2}$ nanomaterials for $\mathrm{CO}_{2}$ conversion/solar fuels. Sol. Energy Mater. Sol. Cells 2012, 105, 53-68. [CrossRef]

22. Raskó, J. FTIR study of the photoinduced dissociation of $\mathrm{CO}_{2}$ on titania supported noble metals. Catal. Letters 1998, 56, 11-15. [CrossRef]

23. Rasko, J.; Solymosi, F. Infrared Spectroscopic Study of the Photoinduced Activation of $\mathrm{CO}_{2}$ on $\mathrm{TiO}_{2}$ and $\mathrm{Rh} / \mathrm{TiO}_{2}$ Catalysts. J. Phys. Chem. 1994, 98, 7147-7152. [CrossRef] 
24. Indrakanti, V.P.; Kubicki, J.D.; Schobert, H.H. Photoinduced activation of $\mathrm{CO}_{2}$ on Ti-based heterogeneous catalysts: Current state, chemical physics-based insights and outlook. Energy Environ. Sci. 2009, 2, 745. [CrossRef]

25. Ramis, G.; Busca, G.; Lorenzelli, V. Structural effects on the adsorption of alcohols on titanium dioxide. J. Chem. Soc. Faraday Trans. 1 Phys. Chem. Condens. Phases 1987, 83, 1591-1599. [CrossRef]

26. Busca, G.; Montanari, T.; Resini, C.; Ramis, G.; Costantino, U. Hydrogen from alcohols: IR and flow reactor studies. Catal. Today 2009, 143, 2-8. [CrossRef]

27. Ramis, G.; Busca, G.; Lorenzelli, V. Low temperature $\mathrm{CO}_{2}$ adsorpion on metal oxides: spectroscopic characterization of some weakly adsoebed species. Mater. Chem. Phys. 1991, 29, 425-435. [CrossRef]

28. Busca, G.; Lorenzelli, V. Infrared spectroscopic identification of species arising from reactive adsorption of carbon oxides on metal oxide surfaces. Mater. Chem. 1982, 7, 89-126.

29. Neatu, S.; Macià-Agullò, J.A.; Concepciòn, P.; Garcia, H. Gold-Copper Nanoalloys Supported on $\mathrm{TiO}_{2}$ as Photocatalysts for $\mathrm{CO}_{2}$ Reduction by Water. J. Am. Chem. Soc. 2014, 136, 15969-15976. [CrossRef]

30. Liao, L.; Lien, C.; Shieh, D.; Chen, M.; Lin, J. FTIR Study of Adsorption and Photoassisted Oxygen Isotopic Exchange of Carbon Monoxide, Carbon Dioxide, Carbonate, and Formate on $\mathrm{TiO}_{2}$. J. Phys. Chem. B 2002, 106, 11240-11245. [CrossRef]

31. Liu, L.; Zhao, H.; Andino, J.M.; Li, Y. Photocatalytic $\mathrm{CO}_{2}$ Reduction with $\mathrm{H} 2 \mathrm{O}$ on $\mathrm{TiO}_{2}$ Nanocrystals: Comparison of Anatase, Rutile, and Brookite Polymorphs and Exploration of Surface Chemistry. ACS Catal. 2012, 2, 1817-1828. [CrossRef]

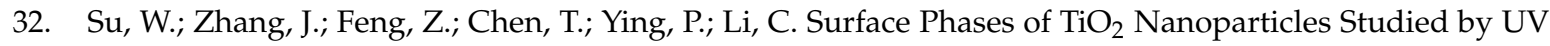
Raman Spectroscopy and FT-IR Spectroscopy. J. Phys. Chem. C 2008, 112, 7710-7716. [CrossRef]

33. Collins, S.E.; Baltanás, M.a.; Bonivardi, A.L. Infrared Spectroscopic Study of the Carbon Dioxide Adsorption on the Surface of Ga2O3 Polymorphs. J. Phys. Chem. B 2006, 110, 5498-5507. [CrossRef] [PubMed]

34. László, B.; Baán, K.; Varga, E.; Oszkó, A.; Erdőhelyi, A.; Kónya, Z.; Kiss, J. Photo-induced reactions in the $\mathrm{CO}_{2}$-methane system on titanate nanotubes modified with $\mathrm{Au}$ and $\mathrm{Rh}$ nanoparticles. Appl. Catal. B Environ. 2016, 199, 473-484. [CrossRef]

35. Chen, L.; Graham, M.E.; Li, G.; Gentner, D.R.; Dimitrijevic, N.M.; Gray, K.A. Photoreduction of $\mathrm{CO}_{2}$ by $\mathrm{TiO}_{2}$ nanocomposites synthesized through reactive direct current magnetron sputter deposition. Thin Solid Films 2009, 517, 5641-5645. [CrossRef]

36. Liu, L.; Gao, F.; Zhao, H.; Li, Y. Tailoring $\mathrm{Cu}$ valence and oxygen vacancy in $\mathrm{Cu} / \mathrm{TiO}_{2}$ catalysts for enhanced $\mathrm{CO}_{2}$ photoreduction efficiency. Appl. Catal. B Environ. 2013, 134-135, 349-358. [CrossRef]

37. Compagnoni, M.; Ramis, G.; Freyria, F.S.; Armandi, M.; Bonelli, B.; Rossetti, I. Innovative photoreactors for unconventional photocatalytic processes: the photoreduction of $\mathrm{CO}_{2}$ and the photo-oxidation of ammonia. Rend. Lincei 2017, 28, S151. [CrossRef]

38. Burcham, L.J.; Badlani, M.; Wachs, I.E. The Origin of the Ligand Effect in Metal Oxide Catalysts: Novel Fixed-Bed in Situ Infrared and Kinetic Studies during Methanol Oxidation . J. Catal. 2001, 203, 104-121. [CrossRef]

39. Whiting, G.T.; Kondrat, S.A.; Hammond, C.; Dimitratos, N.; He, Q.; Morgan, D.J.; Dummer, N.F.; Bartley, J.K.; Kiely, C.J.; Taylor, S.H.; et al. Methyl Formate Formation from Methanol Oxidation Using Supported Gold-Palladium Nanoparticles. ACS Catal. 2015, 5, 637-644. [CrossRef]

40. Montanari, T.; Sisani, M.; Nocchetti, M.; Vivani, R.; Delgado, M.C.H.; Ramis, G.; Busca, G.; Costantino, U. Zinc-aluminum hydrotalcites as precursors of basic catalysts: Preparation, characterization and study of the activation of methanol. Catal. Today 2010, 152, 104-109. [CrossRef]

41. Greaves, J.; Al-Mazroai, L.; Nuhu, A.; Davies, P.; Bowker, M. Photocatalytic methanol reforming on $\mathrm{Au} / \mathrm{TiO} 2$ for hydrogen production. Gold Bull. 2006, 39, 216-219. [CrossRef]

42. Martinez-Ramirez, Z.; Flores-Escamilla, G.A.; Berumen-España, G.S.; Jimenez-Lam, S.A.; Handy, B.E.; Cardenas-Galindo, M.G.; Sarmiento-Lopez, A.G.; Fierro-Gonzalez, J.C. Methanol carbonylation catalyzed by $\mathrm{TiO}_{2}$-supported gold: An in-situ infrared spectroscopic investigation. Appl. Catal. A Gen. 2015, 502, 254-261. [CrossRef]

43. Calzada, L.A.; Collins, S.E.; Han, C.W.; Ortalan, V.; Zanella, R. Synergetic effect of bimetallic Au-Ru/TiO 2 catalysts for complete oxidation of methanol. Appl. Catal. B Environ. 2017, 207, 79-92. [CrossRef] 
44. Kähler, K.; Holz, M.C.; Rohe, M.; Strunk, J.; Muhler, M. Probing the Reactivity of ZnO and Au/ZnO Nanoparticles by Methanol Adsorption: A TPD and DRIFTS Study. ChemPhysChem 2010, 11, 2521-2529. [CrossRef] [PubMed]

45. Manzoli, M.; Chiorino, A.; Boccuzzi, F. Decomposition and combined reforming of methanol to hydrogen: a FTIR and QMS study on $\mathrm{Cu}$ and $\mathrm{Au}$ catalysts supported on $\mathrm{ZnO}$ and $\mathrm{TiO}_{2}$. Appl. Catal. B Environ. 2005, 57, 201-209. [CrossRef]

46. Li, M.; Li, S.; Zhang, C.; Wang, S.; Ma, X.; Gong, J. Ethanol steam reforming over Ni/NixMg1-xO: Inhibition of surface nickel species diffusion into the bulk. Int. J. Hydrog. Energy 2011, 36, 326-332. [CrossRef]

47. Maira, A.; Coronado, J.; Augugliaro, V.; Yeung, K.; Conesa, J.; Soria, J. Fourier transform infrared study of the performance of nanostructured $\mathrm{TiO}_{2}$ particles for the photocatalytic oxidation of gaseous toluene. J. Catalysis 2001, 202, 413-420. [CrossRef]

48. Linsebigler, A.L.; Linsebigler, A.L.; Jr, J.T.Y.; Lu, G.; Lu, G.; Yates, J.T. Photocatalysis on $\mathrm{TiO}_{2} \mathrm{Surfaces}$ Principles, Mechanisms, and Selected Results. Chem. Rev. 1995, 95, 735-758. [CrossRef]

49. Karakas, G.; Yetisemiyen, P. Room Temperature Photocatalytic Oxidation of Carbon Monoxide Over $\mathrm{Pd} / \mathrm{TiO}_{2}-\mathrm{SiO} 2$ Catalysts. Top. Catal. 2013, 56, 1883-1891. [CrossRef]

50. Orlov, A.; Jefferson, D.A.; Macleod, N.; Lambert, R.M. Photocatalytic properties of $\mathrm{TiO}_{2}$ modified with gold nanoparticles in the degradation of 4-chlorophenol in aqueous solution. Catal. Let. 2004, 92, 41-47. [CrossRef]

51. Min, B.K.; Friend, C.M. Heterogeneous gold-based catalysis for green chemistry: low-temperature CO oxidation and propene oxidation. Chem. Rev. 2007, 107, 2709-2724. [CrossRef] [PubMed]

52. Fujishima, A.; Zhang, X.; Tryk, D. TiO 2 photocatalysis and related surface phenomena. Surf. Sci. Rep. 2008, 63, 515-582. [CrossRef]

53. Blount, M.; Falconer, J. Steady-state surface species during toluene photocatalysis. Appl. Catal. B Environ. 2002, 39, 39-50. [CrossRef]

54. Uner, D.; Oymak, M.M. On the mechanism of photocatalytic $\mathrm{CO}_{2}$ reduction with water in the gas phase. Catal. Today 2012, 181, 82-88. [CrossRef]

55. Liu, L.; Zhao, C.; Pitts, D.; Zhao, H.; Li, Y. $\mathrm{CO}_{2}$ photoreduction with $\mathrm{H}_{2} \mathrm{O}$ vapor by porous $\mathrm{MgO}-\mathrm{TiO}_{2}$ microspheres: effects of surface $\mathrm{MgO}$ dispersion and $\mathrm{CO}_{2}$ adsorption-desorption dynamics. Catal. Sci. Technol. 2014, 4, 1539. [CrossRef]

56. Wang, C.; Thompson, R.L.; Ohodnicki, P.; Baltrus, J.; Matranga, C. Size-dependent photocatalytic reduction of $\mathrm{CO}_{2}$ with $\mathrm{PbS}$ quantum dot sensitized $\mathrm{TiO}_{2}$ heterostructured photocatalysts. J. Mater. Chem. 2011, 21, 13452-13457. [CrossRef]

57. Li, K.; An, X.; Park, K.H.; Khraisheh, M.; Tang, J. A critical review of $\mathrm{CO}_{2}$ photoconversion: catalysts and reactors. Catal. Today 2014, 224, 3-12. [CrossRef]

58. Dozzi, M.V.; Prati, L.; Canton, P.; Selli, E. Effects of gold nanoparticles deposition on the photocatalytic activity of titanium dioxide under visible light. Phys. Chem. Chem. Phys. 2009, 11, 7171-7180. [CrossRef] 